\title{
Isotopic Tracers in Coupled Models: A New Paleo-Tool
}

Gavin A. Schmidt ${ }^{1}$, Georg Hoffmann ${ }^{2}$ and Duane Thresher ${ }^{1}$

${ }^{1}$ Columbia University, New York, USA. gschmidt@giss.nasa.gov, dthresher@giss.nasa.gov ${ }^{2}$ LSCE, Gif-sur-Yvette, France. hoffmann@Isce.saclay.cea.fr

\section{General Circulation Model}

Comparing General Circulation Model (GCM) simulations to events seen in the paleo-record is becoming ever more important, yet remains problematic. Since most proxy records reflect multiple influences, some climatic, some biological, unambiguously assigning any one event to a particular cause is generally quite difficult. Thus data-model comparisons are hampered by the fact that they do not compare like with like, i.e. temperatures are compared with $\delta^{18} \mathrm{O}$, overturning strength with benthic $\delta^{13} \mathrm{C}$ ratios etc.

\section{Linking multiple proxies}

The challenge then, is to link multiple proxies and derive a more integrated view of past climate change. Better chronological control, and more proxies will clearly help, but the advent of more sophisticated GCMs should provide a complementary avenue of research. In our opinion, the key to this improvement is the incorporation of the physics and biology associated with the proxy records into the models themselves.

In particular, the ratio of heavy ${ }^{18} \mathrm{O}$ atoms to the lighter ${ }^{16} \mathrm{O}$ variety (denoted by $\delta^{18} \mathrm{O}$ ) is a ubiquitous measurement in paleoclimate research. Many different proxies, all linked by the global hydrological cycle, record the variations in the isotope ratio of the water molecules that originally provided the oxygen, modified by their own unique biogeochemical filters. For example, this ratio is measured in ice cores from the polar ice caps and mountain glaciers, in carbonates taken from foraminiferal shells from marine and lake sediments, in corals and spelotherms, in cellulose taken from tree rings, and in phosphates and silicates, all from widely varying terrestrial and oceanic environments.
GCMs are now capable of simulating these water isotope tracers, both in the atmospheric (Joussaume and Jouzel, 1993; Jouzel et al., 1991 ; Hoffmann et al., 1998), and in the ocean/ice system (Schmidt, 1998; Delaygue et al., 1999). The remaining task is to put these components together in a fully coupled atmosphere-ocean model and combine them with diagnostic modules that attempt to reproduce the filters that ultimately control the signal recorded by the proxy.

\section{Upgrading tracers}

The first stage involves upgrading atmospheric isotopic tracers to incorporate the physics included in state-of-the-art prognostic cloud liquid water and convection schemes. Many processes that are important for the isotopic signal (such as the degree of supersaturation) that were previously estimated independently of the cloud schemes in GCMs, are now treated explicitly, albeit in a parameterized fashion. For the first time, the isotopic signals in precipitation and water vapor should be a fair and accurate representation of the physics contained in the model and thus will start to become useful for diagnosing problems in the cloud schemes as well as for improving our understanding of the isotope response.

\section{A fully coupled water isotope model}

Secondly, given more sophisticated ocean models (including isopycnal mixing, eddy-induced tracer mixing, slope convection, more sophisticated diapycnal diffusion schemes etc.) and the full coupling of freshwater fluxes (precipitation, river and glacial runoff, evaporation, sea ice formation and melting), we have assembled a fully coupled water isotope model that includes all of the processes that affect the seawater $\delta^{18} \mathrm{O}$ signal in a physically consistent way. Of course, this does not guarantee accurate simulations of reality, but does allow us to examine in detail the interactions between the different processes.

However, we are still not done. In order to compare the tracers to the paleo-record, we also need to simulate the processes by which the signals are recorded. Simulating ice cores (e.g. Charles et al., 1994) is relatively simple since there are no biological processes involved. In a slightly more sophisticated fashion, the joint effects of seawater $\delta^{18} \mathrm{O}$ and temperature for coral aragonite or the effects of depth habitat and seasonality for planktonic foraminifera (Schmidt, 1999) can also be simulated. Even a necessarily complicated mechanistic model for $\delta^{18} \mathrm{O}$ in tree ring cellulose (incorporating the ground water, water vapour and the highly fractionated tree water reservoirs (Roden et al., 2000)) can eventually be included.

The first (very!) preliminary coupled results are shown in figures 1 and 2. They show a snapshot of the isotopic concentration in the precipitation field and the associated surface seawater values. Most of the features observable in the real world are also present in the simulation and continuing development will hopefully reduce any substantial discrepencies that may exist.

Further analysis of longer runs will hopefully allow us to see how natural inter-decadal variability of the climate is recorded by the proxies, and what exactly the different proxies are related to. For instance, the deuterium excess value in the ice cores is assumed to be a function of the source region temperature (Merlivat and Jouzel, 1979), however this interpretation is complicated by source region variability, and atmospheric processes [see Noone and Simmonds, this issue]. In the model, such correlations can be clearly delineated and their accuracy and stability quantified.

The next stage will be to perform perturbation experiments such as the addition of meltwater pulses in 


\section{Paleoclimate Modeling}

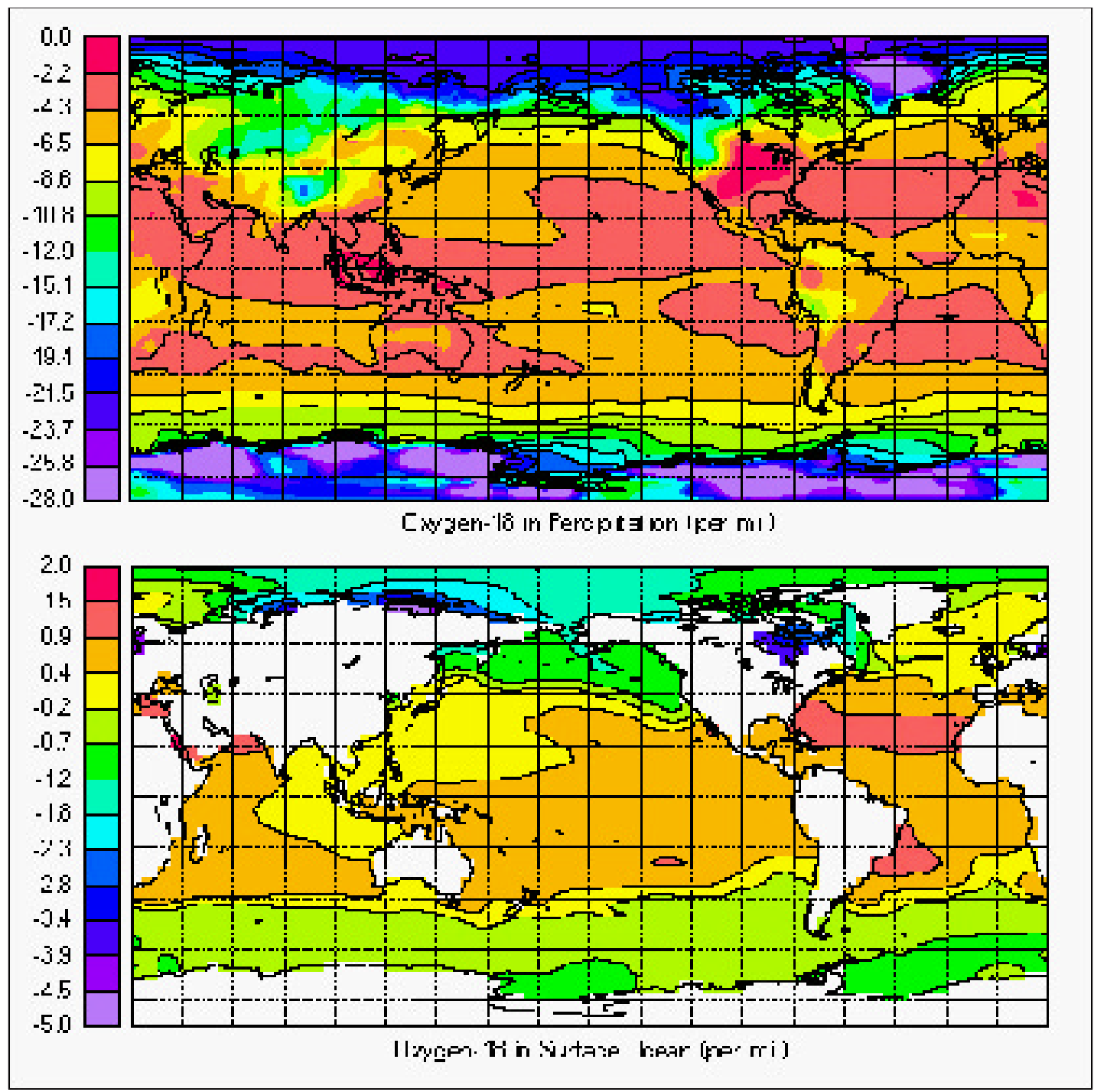

Figure 1: Preliminary results for the present day $\delta^{18} \mathrm{O}$ in precipitation and in the surface ocean from the GISS coupled isotopic tracer model.

the North Atlantic, varying insolation, and LGM experiments. By looking at the transient response of the proxies, we hope to be able to determine the possible leads and lags between the various repositories (such as the Greenland ice cores and North Atlantic sediments), as a function of the climate forcing. This may possibly shed light on the relative chronologies of these disparate paleo-records.

\section{Summary}

In summary, this forward modeling approach is a very powerful method for estimating the fingerprints of various climate forcings and internal variability in many different paleo-isotope repositories. Hopefully, we will be able to use these patterns to deduce likely sets of forcings from the paleo-records themselves and improve our understanding of the links between the terrestrial, oceanic and glaciological systems.

\section{ACKNOWLedgements}

We would like to express our thanks to David Rind and Jean Jouzel who have been unstinting in support of this work. Support for GAS and DT was provided from NSF grant OCE-99-05038.

\section{REFERENCES}

Charles, C.D., D.Rind, J.Jouzel, R.D. Koster, and R.G. Fairbanks, Variable air mass sources for Greenland: Influences on the ice core record, Science, 263, 508-511, 1994

Delaygue, G., J.Jouzel, and J.-C. Dutay, Salinity-oxygen 18 relationship simulated by an oceanic general circulation model, EPSL, 1999, (in press).

Hoffmann, G., M.Werner, and M.Heimann, The water isotope module of the ECHAM Atmospheric General Circulation Model - A study on time scales from days to several years, J. Geophys. Res., 103 16,871-16,896, 1998

Joussaume, S., and J.Jouzel, Paleoclimatic tracers: An investigation using an atmospheric general cir- culation model under ice age conditions, 2, Wate isotopes, J. Geophys. Res., 98, 2807-2830, 1993.

Jouzel, J., R.D. Koster, R.J. Suozzo, G.L. Russell, J.W.C. White, and W.S. Broecker, Simulations of HDO and H2180 atmospheric cycles using the NASA GISS general circulation model: Sensitivity experiments for present-day conditions, J. Geophys. Res., 96, 7495-7507, 1991.

Merlivat, L., and J.Jouzel, Global climatic interpretation of the deuterium-oxygen 18 relationship for precipitation, J. Geophys. Res., 84, 5029-5033, 1979.

Roden, J.S., G.Lin, and J.R. Ehleringer, A mechanistic model for interpretation of hydrogen and oxygen isotope ratios in tree-ring cellulose, Geochim. Cosmochim. Acta, 64, 21-35, 2000.

Schmidt, G.A., Oxygen-18 variations in a global ocean model, Geophys. Res. Lett., 25, 1201-1204, 1998.

Schmidt, G.A., Forward modeling of carbonate proxy data from planktonic foraminifera using oxygen isotope tracers in a global ocean model, Paleoceanography, 14, 482-497, 1999. 